Original Article

\title{
Profile of Patients Attending as Psychiatric Emergency at General Hospital
}

\author{
Tulachan $\mathbf{P}^{1}$, Chapagain $\mathbf{M}^{2}$, Ojha $\mathrm{SP}^{3}$, Dhungana $\mathrm{S}^{4}$
}

1. Lecturer, Department of Psychiatry, TUTH Kathmandu 2. Assoc Prof, Department of Psychiatry, TUTH Kathmandu 3. Assoc. Prof, Department of Psychiatry, TUTH Kathmandu 4. Teaching Assistant, Department of Psychiatry, TUTH Kathmandu

E-mail *Corresponding author: prats38@gmail.com

\begin{abstract}
Introduction: Scaling of services in any area requires knowledge of the pattern of illnesses and their various presentations. We therefore conducted this study aiming to see the pattern of neuropsychiatric illness in an emergency department of tertiary care center. Methods: A prospective study was carried out to assess the pattern of psychiatric morbidity as well as pattern of presenting symptoms in the general emergency room services. Total 340 patients were sought for psychiatric consultation over a period of one and half years from Emergency Room of Tribhuvan University Teaching hospital, Kathmandu. Results: Out of these patients, 281 patients (82.7\%) were found to have diagnosable psychiatric disorder. Most of the patients were in the age group of 31-40 years (25.6\%), and from valley itself $(56.2 \%)$. Males (55.9\%) outnumbered females. Most common presenting symptoms were disturbed behavior and intentional self harm. Out of the patients who received the diagnosis of Category F-Mental and Behavioral disorders of the ICD-10 (82.7\%), 26.8\% were suffering from the Neurotic, stress-related and somatoform disorders and $26.5 \%$ were suffering from Mental and behavioral disorder due to psychoactive substance use. From the remaining $17.3 \%$ of patients, $14.1 \%$ of cases belonged to who attempted intentional self harm and rest were suffering from systemic disorder. Conclusion: Thus, this study emphasizes the importance of clinical and demographic characteristics of patients seeking psychiatric care in emergency service in order provide proper management.
\end{abstract}

Keywords: Psychiatry Emergency, Pattern of illness, Nepal

\section{INTRODUCTION}

The American Psychiatric Association defines a Psychiatric Emergency as a situation that includes an acute disturbance in thought, behavior, mood, or social relationship described by the patient, family, or social unit that requires immediate intervention. ${ }^{1}$ Further elaborated as, any situation caused by these disturbances, in which there is a significant risk of death or serious injury to the patient or to others, thus requiring immediate therapeutic action.

Urgent mental health interventions to tackle these problems are known as Psychiatric emergency services (PES). The major role of Psychiatric Emergency Services (PES) is to cater for patients with acute mental health problems or crisis, after which the patients are discharged to continue treatment in routine mental health settings, minimizing unnecessary inpatient admissions and indirectly being cost effective. ${ }^{2}$

The response to psychiatry emergency depends on the country's available resources. There are three basic models of Psychiatry emergency service delivery: the psychiatric consultant seeing patients in the medical emergency department; a separate section of the medical emergency department dedicated to mental health patients, with specially- 
trained and dedicated staff; and the standalone PES, a facility separate from a medical emergency department that is solely for treatment of acute mental health patients. In a resource poor country like ours, Nepal, it is the first model which applies in the case of most Psychiatry Emergency Services. ${ }^{2}$

Studies regarding psychiatric emergency services have focused on various aspects. There has been a rapid increase in patients utilizing the Psychiatric Emergency Service. Western literatures report, whether due to the long-term effects of deinstitutionalization, inadequate community resources, the large numbers of uninsured individuals, or other causes, it is inarguable that emergency department presentations of psychiatric problems are on the rise. ${ }^{3}$ From 1992 to 2001, in the United States, there was a substantial increase in the number of visits to emergency units due to psychiatric conditions (from 17.1 to 23.6 per 1000 inhabitants). ${ }^{4}$

Symptoms and conditions behind psychiatry emergency may include attempted suicide, substance dependence, alcohol intoxication, acute depression, presence of delusions, violence, panic attacks, and significant, rapid changes in behavior. Studies have shown patients with chronic or acute psychosis (schizophrenia/bipolar disorder/psychosis of unknown origin), substance abuse and personality disorders constitute a large part of the typical PES diagnostic profile. 5,6

There are studies showing wide range of concomitant medical disorders $7 \%$ to $63 \%$ in emergency presenting as Psychiatric emergencies. ${ }^{7}$ Medical disorders are considered causative of psychiatric symptoms so need of medical screening is must. In addition misdiagnosis and the application of psychiatric labels to medically ill patients can have ethical and legal significance as it reduces their chances of improvement and may result in worsening of their physical health, inappropriate hospitalization in a psychiatric facility, and social stigma. ${ }^{8,9}$

Studies conducted in western countries have found that ethnic minorities, immigrants, and patients with low socioeconomic status and poor social support are more likely to use PES excessively. ${ }^{10}$

There are studies showing excessive use of PES for nonurgent problems as well. ${ }^{11,12}$ For many patients, the PES served as the only mental health treatment source ${ }^{13}$ and in some studies it partly reflected the poor access to routine mental health care in the country. 11,12

In Nepal, literature regarding psychiatric emergency is scarce. Above mentioned varied challenges genuinely demand need for evaluation in various areas, in our context, in order to improve the level of care offered from the Psychiatric emergency services. Thus present work was done to study the sociodemographic and diagnostic profile of patients for whom psychiatric consultation was sought in Emergency Room.

\section{MATERIAL AND METHOD}

A prospective study was carried out on patients attending general emergency room services of Tribhuvan University Teaching Hospital, Maharajgunj, Kathmandu, a tertiary care hospital, from mid July, 2012 to mid February, 2014. All the patients who were referred to Psychiatry Resident by the Emergency Medical Officer were included in the study group. A self designed proforma was used to record the socio-demographic data and information about the illness (diagnosis, symptom presentation).The final psychiatric diagnosis was made by a qualified Psychiatrist according to the 10th edition of 'International Classification of Disease and Infirmity' (ICD-10). ${ }^{14}$

\section{RESULT}

Table 1: Age and sex distribution

\begin{tabular}{|c|c|c|c|c|}
\hline \multirow{2}{*}{$\begin{array}{c}\text { Age in } \\
\text { Years }\end{array}$} & \multicolumn{2}{|c|}{ Sex } & \multicolumn{2}{c|}{ Total } \\
\cline { 2 - 5 } & female & male & N & $\%$ \\
\hline$<11$ & 0 & 1 & 1 & 0.29 \\
\hline $11-20$ & 49 & 21 & 70 & 20.5 \\
\hline $21-30$ & 39 & 44 & 83 & 24.4 \\
\hline $31-40$ & 31 & 56 & 87 & 25.5 \\
\hline $41-50$ & 15 & 33 & 48 & 14.1 \\
\hline $51-60$ & 9 & 19 & 28 & 8.2 \\
\hline$>61$ & 7 & 16 & 23 & 6.7 \\
\hline Total & 150 & 190 & 340 & 100 \\
\hline
\end{tabular}


Table 2: Diagnostic Distribution

\begin{tabular}{|c|c|c|c|}
\hline & Diagnosis & frequency & $\%$ \\
\hline & $\begin{array}{l}\text { F 00- 09:Organic ,Including } \\
\text { Symptomatic, mental } \\
\text { disorders }\end{array}$ & 23 & 6.8 \\
\hline 里 & $\begin{array}{l}\text { F 10-19:Mental and } \\
\text { behavioural disorders due } \\
\text { to psychoactive substance } \\
\text { use }\end{array}$ & 90 & 26.5 \\
\hline 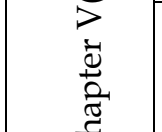 & $\begin{array}{l}\text { F 20-29:Schizophrenia, } \\
\text { schizotypal and delusional } \\
\text { disorders }\end{array}$ & 50 & 14.7 \\
\hline $\begin{array}{l}\overrightarrow{0} \\
\stackrel{1}{0} \\
\dot{0}\end{array}$ & $\begin{array}{l}\text { F 30-39:Mood [affective] } \\
\text { disorders }\end{array}$ & 26 & 7.6 \\
\hline 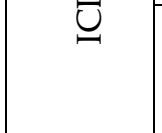 & $\begin{array}{l}\text { F 40-48: Neurotic, stress- } \\
\text { related and somatoform } \\
\text { disorders }\end{array}$ & 91 & 26.8 \\
\hline & $\begin{array}{l}\text { F50 -59:Behavioural } \\
\text { syndromes associated with } \\
\text { physiological disturbances } \\
\text { and physical factors }\end{array}$ & 1 & 0.3 \\
\hline$\approx \bar{\sigma}$ & $\begin{array}{l}\text { Diseases of the nervous } \\
\text { system }\end{array}$ & 5 & \\
\hline 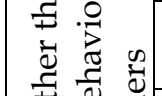 & $\begin{array}{l}\text { Diseases of the circulatory } \\
\text { system }\end{array}$ & 3 & 3.2 \\
\hline 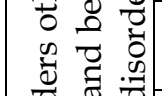 & $\begin{array}{l}\text { Diseases of the } \\
\text { genitourinary system }\end{array}$ & 1 & \\
\hline$\frac{\sigma}{0} \frac{\pi}{\pi}$ & Accidental cases & 2 & \\
\hline$\vec{D} \stackrel{\Xi}{\Xi}$ & Intentional self harm & 48 & 14.1 \\
\hline
\end{tabular}

Table 3: Common presentation for psychiatric consultation

\begin{tabular}{|l|c|c|}
\hline \multicolumn{1}{|c|}{ Presentation } & Frequency & $\mathbf{\%}$ \\
\hline Acute anxiety & 38 & 11.2 \\
\hline Altered consciousness & 50 & 14.7 \\
\hline Disturbed behavior & 65 & 19.1 \\
\hline Mood symptoms & 12 & 3.5 \\
\hline $\begin{array}{l}\text { Physical/somatic } \\
\text { complaints }\end{array}$ & 58 & 17.1 \\
\hline $\begin{array}{l}\text { Intentional Self harm } \\
\text { Substance related } \\
\text { problems }\end{array}$ & 65 & 19.1 \\
\hline others Total & $\mathbf{3 4 0}$ & $\mathbf{1 0 0}$ \\
\hline \multicolumn{2}{|c|}{} \\
\hline
\end{tabular}

Total number of patients referred for psychiatric consultation from emergency room for the above mentioned period was 340 patients. Although no age is spared from the psychiatric illnesses, our result showed that among total patients more than half of the patients were from 11years to 40 years age group. Majority of them were males and majority of them were from Kathmandu valley. Ethnicity wise there were more hindus $(55.3 \%)$ followed by janjatis (30.9\%). Educational background showed most of the patients was literate till certificate level $(29.4 \%)$ and students $(26.8 \%)$ outnumbered other occupation profile.

The most common symptom(s) for which patient was brought to the emergency were disturbed behavior and intentional self harm, followed by physical/somatic complaints, substance related problems, altered consciousness and acute anxiety.

The most common presentation for psychiatric consultation was for intentional self harm. Among them 10.7\% were diagnosed as Mood disorders, 9.2\% were diagnosed Neurotic, stress-related and somatoform disorders, $4.6 \%$ diagnosed as Mental and Behavioral disorders due to substance use and majority $73.8 \%$ had no psychiatric diagnosis. Result shows, majority of patients who presented with intentional self harm fell into youth group and female outnumbered male.

Two hundred and eighty one $(82.7 \%)$ patients received the diagnosis of Category F- Mental and Behavioral disorders of the ICD-10. Among them, $26.8 \%$ were suffering from the Neurotic, stress-related and somatoform disorders, 26.5\% were from Mental and Behavioral disorders due to psychoactive substance use. About $14.7 \%$ were suffering from Schizophrenia and other psychotic disorders, $7.6 \%$ were suffering from Mood disorders, $6.8 \%$ were suffering from Organic, including symptomatic, mental disorders and $0.3 \%$ suffering from Behavioral syndromes associated with physiological disturbances and physical factors.

\section{DISCUSSION}

Psychiatric Emergency have now evolved into a separate subspecialty considering the clinical and social challenges involved with it. Thus it 
warrants an extensive research regarding this field in order to understand psychiatric emergencies and to improvise the services. In this light, there are only few exclusive Nepalese studies till now and perhaps this study would give some contribution in the same area.

Regarding the patient's sociodemographic profile, this study showed that they were preponderantly males and more than 50\% cases belonged to age range 11-40 years. This profile is similar to what was described in other study conducted in Nepal and elsewhere. ${ }^{15,16}$ However it differed from one study from Nepal ${ }^{17}$ and studies from western side. ${ }^{18,19}$ These described a predominance of female patients. This discrepancy was probably due to the characteristics that in our study and others, a significant portion of the patients were diagnosed having substance related problem, which ended up being more compatible with the profile described. Additionally some studies describe that males use psychiatric emergency services more than women, and are more often admitted to the hospital. ${ }^{20}$

The most prevalent ethnic backgrounds were Hindus and Janjatis, which outnumbered other ethnicities. This finding was consistent with other study from Nepal. ${ }^{15}$ The reason for discrepancy could be that similar population distribution exists in same area but this reason may not be sufficient. Probably this area is complex, and needs to be explored in our country. However, in western side there are studies that show, racial disparity existed in patterns of how mental health services were utilized which could be the other reason. ${ }^{21,22}$

Majority of patients were from Kathmandu itself. Tribhuvan University Teaching Hospital, located in Kathmandu is semi government tertiary care hospital that have been providing best care within affordable expenses including comprehensive psychiatric services, this could be the reason for majority of patients being from the city.

A significantly greater proportion of patients having education just up to the certificate level and preponderance of students without employment would infer the possibility of role of these psychosocial stressors as the risk factor for psychiatric emergencies. In our setting there is a paucity of researches as to show how psychosocial stressors affect ones mental health. However there are studies from western side which clearly shows psychosocial stressors like education, employment, socioeconomic status, and relationship conflict were one of the main characteristic features of individuals at higher risk for psychiatric emergency. ${ }^{23,24}$

Comparing the main reasons for seeking psychiatric emergency consultations the data showed similarities with other countries 25,26 and from Nepal. ${ }^{15}$ Intentional self harm (19.1\%) and disturbed behavior (19.1\%) were the most prevalent presenting symptoms. Moreover, the number it has shown, regarding intentional self harm could be less, as it did not include those who after attempting suicide developed serious medical complications or who needed intensive medical treatment.

The significant upsurge of intentional self harm cases in Emergency compared to previous literature from same setting has brought attention. The rate in present study was $19.1 \%$ whereas in previous study was $6.7 \% .{ }^{17}$ This difference is may be due to improved consultation liaison system within the Psychiatry and Emergency departments or it could be due to true increment in the self harm rate which further needs exploration. In addition $73.8 \%$ of cases who intentionally self harmed, they were cases who had first attempt of self harm as an impulsive act following an acute psychosocial stressor, were not labeled any psychiatric diagnosis and most of them belonged to youth group. This further warrants thorough investigation for possible explanations of why productive younger individuals had high self harm rates. Was it because of peaking psychological issues related to this age group such as educational problems, unemployment, socioeconomic problems, problems related with relations or just issues of personality as suggested in western literatures. 27,28

Regarding diagnosis the Neurotic, stressrelated and somatoform disorders $(26.8 \%)$ and Mental and Behavioral disorders due to psychoactive substance use (26.5\%) predominated the whole picture followed by Schizophrenia and other psychotic disorders (14.7\%).This predominance has also been demonstrated in other studies 15,16,17,29 which reflects the growing problem due to stress related disorders and psychoactive substance use.

In this study, $3.2 \%$ of cases for which psychiatric consultation was sought were 
purely for medical problem and $6.8 \%$ of cases presented with psychiatric syndromes due to medical problem. It is important to consider frequency and severity of medical syndromes that mimic, complicate or accompany mental illness as different literature suggest its contribution varies from $15-90 \% .7,30$ Therefore, "Medical clearance" of psychiatric patients, the initial medical evaluation of patients in the emergency room is must, in order to determine whether serious underlying medical illness exists.

It is important to take into consideration of some limitations of this study. The first one is, there could be underrepresentation of cases as it is hospital based study in a very busy hospital. Therefore in sense of pressure or prioritization, there is possibility of cases being inadequately dealt in emergency and disposed without psychiatric consultation. Similarly, establishing a psychiatric diagnosis requires longitudinal follow-up and in emergency setting it is simply based on clinical presentation and on additional information from the patient and the accompanying person. Therefore the diagnosis made may not be the final diagnosis. Lastly, there are literatures that have mentioned a quite proportion of patients in Emergency with diagnosis of Personality disorders especially cases with intentional self harm. ${ }^{31,32}$ However, in our study, Personality disorder was not a primary diagnosis, which could be due to inadequate evaluation or non availability of reliable informant.

\section{CONCLUSION}

The findings that we have presented in this study suggest that there is still need to pursue further researches in different aspects of Psychiatric Emergency in our context. From sociodemographic variables to psychosocial stressors to factors leading for attempt of intentional self harm. Appropriately identifying specific characteristics of individuals, who seek such services, will enable us to have better understanding of the presenting population with the goal of providing the best possible care to them.

\section{REFERENCE}

1. Williams E, Shepherd S. Medical clearance of psychiatric patients.Emerg Med Clin North Am 2000;18:185-98.
2. Scott L. Zeller, MDTreatment of Psychiatric Patients in Emergency Settings. Primary Psychiatry. 2010;17(6):35-41

3. Hazlett SB, McCarthy ML, Londner MS, Onyike CU. Epidemiology of adult psychiatric visits to US emergency departments. Acad Emerg Med. 2004;11(2):193-195.

4. Larkin GL, Claassen CA, Emond JA, Pelletier AJ, Camargo CA. Trends in U.S. emergency department visits for mental health conditions, 1992 to 2001. Psychiatr Serv. 2005;56(6):671-7.

5. Chaput Y, Lebel MJ: Demographic and clinical profiles of patients who make multiple visits to psychiatric ermegency services. Psychiatr Serv 2007, 58:335-341.

6. Pasic J, Russo J, Roy-Byrne P: High utilizers of psychiatric emergency services. Psychiatr Serv 2005, 56:678-684

7. Gregory R, Nihalani N, Rodriguez E. Medical screening in the emergency department for psychiatric admissions: a procedural analysis. Gen Hosp Psychiatry 2004;26:405-10.

8. Hall R, Popkin M, Devaul R, Faillace L, Stickney S. Physical illness presenting as psychiatric disease. Arch Gen Psychiatry 1978;35:1315-20.

9. Hall R, Gardner E, Stickney S, LeCann A, Popkin M. Physical illness manifesting as psychiatric disease. Arch Gen Psychiatry 1980;37:989-95.

10. L. R. Snowden, M. C. Masland, A. M. Libby, N. Wallace, and K. Fawley, "Racial/ethnic minority children's use of psychiatric emergency care in California's public mental health system," American Journal of Public Health, 2008 vol. 98, no. 1, pp. 118-124.

11. R. Catalano, W. McConnell, P. Forster, B. McFarland, and D. Thornton, "Psychiatric emergency services and the system of care," Psychiatric Services,2003 vol. 54, no. 3, pp. 351-355.

12. L. R. Snowden, R. Catalano, and M. Shumway, "Disproportionate use of psychiatric emergency services by African Americans," Psychiatric Services,2009 vol. 60, no. 12, pp. 1664-167.

13. Strakowski, S. M., Lonczak, H. S., Sax, K. W., West, S. A., Crist, A., Mehta, R., et al. The effects of race on diagnosis and disposition from a psychiatric emergency service. Journal of Clinical Psychiatry, 1995 56(3), 101-107.

14. World Health Organization. International Classification of Diseases and Related Health Problems-Tenth Edition. Chapter V- Mental and Behavioral Disorders: Clinical Description and Diagnostic 
Guidelines. Geneva: World Health Organization 1992.

15. Shakya DR, Shyangwa P M, Shakya R.Psychiatric Emergencies in a Tertiary Care Hospital. J Nepal Med Assoc 2008;47(169):28-33

16. Sidana A, Sharma RP, Chavan BS, Arun $P$, Lok Raj L.Psychiatric Patients in Emergency. Journal of Mental Health \& Human Behavior, 2009; 14(2) : 80-83.

17. Khalid A, Regmi SK, Koirala NR, Nepal MK and Pokharel A. Psychiatric Emergencies in a General hospital setting.Journal of the Institute of Medicine 1999; 21: $1-214$

18. Santos MESB, Amor JA, Del-Ben CM, Zuardi AW. Serviço de emergências psiquiátricas em hospital geral universitário: estudo prospectivo [Psychiatric emergency service in a school general hospital: a prospective study]. Rev Saúde Pública. 2000;34(5):468-74.

19. Sousa FSP, Silva CAF, Oliveira EN. Serviço de emergência psiquiátrica em hospital geral: estudo retrospectivo [Emergency psychiatric service in general hospitals: a retrospective study]. Rev Esc Enferm USP. 2010;44(3):785-91.

20. Saarento, O., Rasanen, S., Nieminen, P., Hakko, H., \& Isohanni, M. Sex differences in contact rates and utilization of psychiatric services: A three-year followup study in Northern Finland. European Psychiatry,2000. 14, 205-212

21. Jimenez DE, Cook B, Bartels SJ, Alegría M.Disparities in mental health service use of racial and ethnic minority elderly adults.J Am Geriatr Soc. 2013Jan;61(1):1825.

22. Chun-Chung Chow J, Jaffee K, Lonnie Snowden L. Racial/Ethnic Disparities in the Use of Mental Health Services in Poverty Areas. Am J Public Health. 2003 May; 93(5): 792-797.

23. Strakowski, S. M., Lonczak, H. S., Sax, K. W., West, S. A., Crist, A., Mehta, R., et al. The effects of race on diagnosis and disposition from a psychiatric emergency service. Journal of Clinical Psychiatry1995; 56(3), 101-107.

24. Hatfield, B., Perry, A., \& Spurrell, M. Emergency referrals to an acute psychiatric services: Demographic, social, and clinical characteristics and comparisons with those receiving continuing services. Journal of Mental Health 200; 9(3), 305-318.

25. Anstee B H. Psychiatry in the Casualty Department.Br J Psychiatry 1972; 120: 6259.

26. MadsenTE, Bennett A, Groke S, Zink A, McCowan C, Hernandez A, Knapp S,
Byreddy D, Mattsson S, Quick N Emergency Department Patients with Psychiatric Complaints Return at Higher Rates than Controls West J Emerg Med. Nov 2009; 10(4): 268-272.

27. Bahattin Işık, Muhittin Serkan Yilmaz, Cihat Yel , Cemil Kavalci, Gulsum Kavalci ,Yunsur Cevik, Burak Demirci, Miray Özlem, Bedriye Muge Sonmez

Retrospective assessment of patients over 15 years of age presenting to emergency department with a suicide attempt.Science Journal of Clinical Medicine 2014; 3(2): 2428

28. Güloglu C, Gökhan S, Ustündag M, Orak M. Effects ofsuicide methods and demographic data on mortality in patients presented with suicide attempts to the emergency department. Tr J Emerg Med. 2009; 9: 109-14.

29. Padilha VM, Schettini CSS, Junior AS, Azevedo RCS. Profile of patients attended as psychiatric emergencies at a university general hospital Sao Paulo Med. J.2013 vol.131 no.6

30. Gregory R, Nihalani N, Rodriguez E. Medical screening in the emergency department for psychiatric admissions: a procedural analysis. Gen Hosp Psychiatry 2004;26:405-10.

31. D.C. de la Vega, A.Arcenegui Calvo Drug overdosing, personality disorder and selfinjurious behavior European Psychiatry 2013 Volume 28, Supplement 1, Page 1.

32. Kumar A, Kakati AK, Nath K, Das S. Psychiatric consultation in out-of-hours casualty/emergencydepartment. Dysphrenia. 2012;3:149-52. 